\title{
DIREITOS HUMANOS COMO RECONSTRUÇÃO DO DIREITO NATURAL SOBRE O POSITIVISMO? VELHOS PROBLEMAS E VELHAS SOLUÇÕES
}

\author{
Carlos Marden ${ }^{1}$
}

Taís Vasconcelos Cidrão ${ }^{2}$

\section{RESUMO}

O presente trabalho tem como objetivo precípuo a investigação, através de um estudo bibliográfico, de um velho problema e como a comunidade jurídica está introduzindo uma "nova" solução para essa discussão entre o Direito Natural e Direito Positivo. A nova cruzada, que é a dos Direitos Humanos, tem sido utilizada não só para dar uma nova roupagem ao Direito Natural, mas também para conseguir resgatar os mesmos problemas de ordem subjetiva se utilizando, para tanto, apenas de novos rótulos e que já foram superadas pelo positivismo jurídico.

Palavras-chave: Direitos Humanos. Positivismo Jurídico. Direito Natural. Filosofia do Direito. Positivação.

\section{HUMAN RIGHTS AS A RECONSTRUCTION OF NATURAL LAW OVER POSITIVISM? OLD PROBLEMS AND OLD SOLUTIONS}

\begin{abstract}
The present work has as its main objective the investigation, through a bibliographic study, of an old problem, which is a discussion between Natural Law and Positive Law, in this scenario it is investigated how a legal community is introducing a "new" solution to this discussion. The new Crusade, which is Human Rights, has been used not only as a new coat to Natural Law, but also to recover the same subjective problems only by using new labels that have already been surpassed by the Legal positivism.
\end{abstract}

Keywords: Human Rights. Legal Positivism. Natural Law. Philosophy of Law. Positivation.

\footnotetext{
${ }^{1}$ Procurador Federal. Especialista em Direito Processual Civil e Mestre em Ordem Jurídica Constitucional pela Universidade Federal do Ceará. Doutor em Direito Processual pela Pontifícia Universidade Católica de Minas Gerais. Pós-doutorando em Estado, Constituição e Democracia pela Universidade do Vale do Rio dos Sinos.

2 Mestranda em Direito pelo Programa de Mestrado em Direito do Centro Universitário Christus (UNICHRISTUS). Graduada em Direito pela Universidade de Fortaleza (UNIFOR), aluna de especialização em Direito e Processo Constitucionais pela UNIFOR. E-mail: <taisvcidrao@ hotmail.com>.
} 


\section{INTRODUÇÃO}

Durante muito tempo se discutiu acerca de um Direito Natural. Isso quer dizer, uma ideia mais abstrata de Direito que se traduz como uma ordem "ideal" capaz de consagrar justiça e aquilo que é “correto", sem, no entanto, depender de variações ocorridas dentro de cada sociedade (imutáveis, portanto). Não é por acaso que o próprio nome sugere uma origem, uma natureza, uma essência. Essa origem, entretanto, não é convencionada ao certo, isto é, pode ela advir inclusive, segundo alguns, da vontade divina. Essa concepção de Direito leva em consideração direitos que são universais e comuns a todos os seres humanos.

Entretanto, com o surgimento do Direito Positivo (tido como um conjunto de regras jurídicas escritas ou não e posto pelo Estado) como uma verdadeira necessidade para regular a vida social que, com o passar do tempo, se tornou cada vez mais complexa, começou-se a enxergar o Direito Natural. Essa nova perspectiva foi vista não mais sob um aspecto objetivo de regulação do convívio, mas sim como um contrapeso à ação legiferante do Estado, ou seja, um subsídio do qual faz uso o cidadão para a reivindicação de direitos, e por esse motivo passando a ter uma índole subjetiva.

Para se atingir o objetivo do presente artigo, devem-se considerar não apenas o debate milenar entre Direito Natural (que se desenvolve desde Platão, Aristóteles, retomado por Tomás de Aquino e outros depois dele) e Direito Positivo, mas também diversas explicações acerca da crescente e intensa atenção dada aos Direitos Humanos na atualidade, bem como a sua extensa amplitude internacional. Isso não seria possível, entretanto, sem trazer à tona discussão acerca da filosofia do Direito, especialmente no que toca a separação epistemológica entre Ciência do Direito e Moral.

A nova cruzada, que é a dos Direitos Humanos, tem enfrentado cada vez mais desafios não só conceituais, mas também normativos e principalmente políticos. Em verdade, até mesmo a reivindicação de universalidade advinda do próprio termo utilizado foi posta em cheque por estudiosos do Direito Internacionais, que se opõem aos compromissos seculares e individualistas.

Já há algum tempo, o avanço da positivação do próprio Direito Internacional Público ao redor do mundo, que se deu especialmente após o fim da Segunda Guerra Mundial, tem tentado carregar consigo uma concepção positivista no âmbito dos Direitos Humanos. Mas será mesmo

Revista de Teoria e Filosofia do Estado | e-ISSN: 2525-9652 | Maranhão | v. 3 | n. 2 | p. 41 - 57 | Jul/Dez. 2017. 
essa jornada possível? Essa foi a pergunta-problema que deu origem à discussão do presente artigo. Para responder tal questionamento, foram analisadas as teorias (e seus posteriores aperfeiçoamentos e refinamentos) acerca do Direito Natural e do Direito Positivo ao longo do tempo e, depois, feita uma reflexão sobre como os Direitos Humanos tomam lugar dentro dessa discussão.

\section{A TEORIA DO DIREITO NATURAL}

Dentro da discussão acerca da filosofia do direito, surge uma concepção de teoria natural que remonta à ideia de que a lei não deveria possuir falhas, pois sua natureza transcende aquilo que está ao alcance do homem no mundo dos fatos. Essa ideologia pode ser traduzida no seguinte: fazei o bem. É dele que emana as reais obrigações dos homens entre si e perante Deus.

A lei divina e eterna, nesse caso, seria responsável por regular toda a vida mundana; cabendo à ciência do direito, portanto, apenas a tarefa de adequar o mundo dos homens a essa lei. Essa lei, por óbvio, só poderia advir de uma fonte não-humana (ou melhor: sobre-humana), qual seja: Deus, do qual provém a harmonia de todo o universo. A teoria do Direito Natural se justifica pelo seu fim último, que é o próprio valor de justiça. Para tanto, procura-se classificar as condutas em justas ou injustas (boas ou ruins). Essa “qualificação moral” é, não só condição suficiente, mas também necessária para que o Direito possa legitimamente regular as condutas sociais.

A grande diferença entre a lei natural e a lei positiva é que, esta última encontra sua gênese no bel-prazer do Homem. Por outro lado, a lei natural trabalha em cima daquilo que é justo e imutável no tempo e no espaço, e por esse motivo, independe de qualquer alteração que porventura passa aparecer na lei humana.

A teoria do Direito Natural está divida em duas grandes "fases", são elas: a do pensamento antigo e a teoria natural moderna. Há certa homogeneidade entre a primeira fase do pensamento naturalista, (caracterizada pelas obras de Tomás de Aquino, Platão, Aristóteles), e o pensamento cristão, pois a crença religiosa de que o mundo era regido por uma lei de Deus (pensamento típico da Igreja Católica) era bastante difundida durante a Idade Média. Essa Lei Natural era pensada como teologia por se predominar o império da fé. É nesta fase do Direito 
Natural que opera o processo "encantamento" do mundo (que seria desmistificado por Max Weber ${ }^{3}$ no século XIX).

Há, nessa fase, uma divisão entre dois movimentos, quais sejam: a patrística (séculos II a VI) e a escolástica (séculos IX a XV). O principal representante da primeira foi Santo Agostinho, até hoje considerado um grande nome dentro da filosofia. Durante esse período, os padres da Igreja Católica difundiam seus dogmas (ou especulações) para expor a religião católica.

Já na escolástica, Tomás de Aquino surge com um discurso de justiça como uma virtude geral. Em que pese o apego a um dogma religioso, ele consegue distinguir três tipos de leis que, em conjunto, são capazes de dirigir o mundo: a lei natural, responsável pela coordenação do cosmo e conservação da vida; a lei humana, aquelas criadas com base na lei natural e dirigida ao bem comum, ou seja, ao governo dos homens para manter a paz; e por fim, a lei divina, aquela responsável por guiar o homem ao seu fim sobrenatural (MATTOS, 2000, p. 13).

Já a partir do século XVI-XVII, com o processo de racionalização que foi surgindo de maneira gradual, a ciência do Direito Natural sofreu uma ruptura na sua compreensão. Uma espécie de jusracionalismo surgiu, situação que começou a irromper uma nova busca para o fundamento da lei divina, eterna e imutável, qual seja, a razão. Um dos principais representantes dessa nova fase do jusnaturalismo foram Thomas Hobbes e John Locke. Nesse contexto, era possível sim a tarefa de criação de uma lei humana, desde que se ajustassem às leis naturais, que se evidenciam ao homem.

\footnotetext{
Chega-se a um resultado semelhante ao olhar não para a estrutura formal da normal, mas para o fim. A resposta mais comum, dada há séculos, à pergunta sobre qual é o fim do Direito, é que ele consiste na conservação da sociedade humana. A teoria do Direito Natural nos ensina com certeza pelo menos uma coisa: que o direito natural não serve para esse fim. Por direito natural, os jusnaturalistas entendem aquele vigente no estado de natureza. Pois bem, é teoria comum a todo o jusnaturalismo dos séculos XVII e XVIII que o estado natural é impossível, e isso é exatamente porque as leis naturais, sozinhas, não têm condições de garantir aos homens em sociedade a segurança de sua existência (BOBBIO, 2016, p. 200).
}

\footnotetext{
${ }^{3}$ Significa principalmente, portanto, que não há forças misteriosas incalculáveis, mas que podemos, em princípio, dominar todas as coisas pelo cálculo. Isto significa que o mundo foi desencantado. Já não precisamos recorrer aos meios mágicos para dominar ou implorar aos espíritos, como fazia o selvagem, para quem esses poderes misteriosos existiam. Os meios técnicos e os cálculos realizam o serviço. (WEBER, 1982,p. 165).
} 
Essa transição, ainda que "suave", foi o primeiro passo rumo ao antropocentrismo (quer dizer, a partir de então o homem começou observando-o a partir de si mesmo e não pelos olhos de Deus), de forma que as explicações não são mais dadas pela natureza, mas sim, pela própria razão do ser humano. Esse novo conhecimento é o que, mais a frente, e dentre outros motivos, desencadeará nas revoluções liberais, mais especificamente a estadunidense (1776) e a Revolução Francesa em 1789, que rompe completamente com o Ancien Régime, começando uma nova era de positivação dos Direitos Humanos ${ }^{4}$.

O jusnaturalismo contemporâneo reconheceu críticas feitas a ele ainda no século XIX. Tendo repensado a própria relatividade do conceito de justiça, e que ela poderá ser valorada de diferentes formas. Dessa forma, aquele antigo conceito de justiça imutável e perene se esvaziou, já que há diferentes formas de se vivenciar o justo. "O conteúdo do que seja direito justo variará, contudo, no tempo e no espaço, ao sabor das exigências valorativas de cada cultura humana" (SOARES, 2008, p. 46).

De todo modo, o Direito Natural serviu para sinalizar a importância (se não a necessidade) de uma instância valorativa do Direito, ainda que confunda o Ser com o DeverSer, ou seja, achar que o conceito de justiça deva ser equivalente ao conceito de Direito (o que de fato não ocorre), a injustiça também é englobada pelo Direito.

O progresso científico-racional, uma vez prometido pelo movimento iluminista (com influências de Voltaire, Rousseau, Montesquieu e outros que ajudaram a implementar a ciência da razão), conseguiu ser sustentado pela doutrina do Direito Natural por muito tempo.

"No mundo moderno o paradigma do Direito Natural foi capaz de lidar, até o século
XVIII, com os problemas da crescente secularização, sistematização, positivação,
historicização do Direito, mas a intensidade destes processos levou à sua erosão. Daí
o aparecimento de um novo paradigma: o da Filosofia do Direito" (LAFER, 1988, p.
16).

Essa doutrina não conseguiu oferecer, de forma satisfatória, uma proposta acerca da compreensão do alcance do Direito. Não surpreendentemente, esse cenário sofreu alterações, situação que deu azo ao surgimento do movimento positivista.

\footnotetext{
${ }^{4}$ Nessa época, os ideais de Liberdade, Igualdade e Fraternidade passaram a se difundir em contraposição ao Estado absolutista.
} 


\section{A SUPERAÇÃO DO DIREITO NATURAL PELO DIREITO POSITIVO}

Com a transição da sociedade medieval para o Estado moderno e com a monopolização do mundo jurídico pelo Estado, no início do século XIX, na França e também na Inglaterra, começou-se a evidenciar a importância da realidade fática, e o mais importante: como a metafísica e a teologia não inspiravam uma explanação razoável o suficiente para o problema das normas jurídicas.

O novo paradigma da Filosofia do Direito é uma resposta ao processo da crescente
positivação do Direito pelo Estado - um processo que realçou o papel do Direito como
instrumento de gestão e comando da sociedade através da técnica das ordens e
proibições, dos estímulos e desestímulos às condutas humanas. Por isso, o Direito
deixou de ser encarado como algo dado pela razão comum e que permite qualificar
condutas como boas ou más. [...] Daí a mutabilidade do Direito no tempo e o seu
particularismo no espaço, situação que, ao se ver generalizada diluiu a relevância do
paradigma do Direito Natural (LAFER, 1988, p. 17).

Assim, com a ajuda da divulgação pela Escola da Exegese, houve a criação do positivismo jurídico (moldado ao longo do século XX quando em contato com as ciências sociais), que de forma alguma pode ser entendido como a redução do Direito àquilo que está positivado.

Efetivamente, o que se tem é a concentração do poder de criar o Direito nas mãos do próprio Estado. O que é bem diferente de se reduzir ao que está de fato impresso na lei, pelo simples motivo de que o Estado pode criar Direito 1) de forma direta, nesse caso sim, através da leis positivas, mas também 2) indiretamente, através do reconhecimento e controle das normas consuetudinárias ${ }^{5}$. Esse é o que Bobbio chamou de "processo de monopolização da produção jurídica por parte do Estado” (BOBBIO, 2006, p. 27).

Segundo as palavras que Norberto Bobbio (2016, p. 156) escolheu para diferenciar as duas teorias, quais sejam, positiva e natural, "o jusnaturalismo afirma a superioridade do direito natural sobre o positivo, o positivismo não afirma a superioridade do direito positivo sobre o

\footnotetext{
5“A fórmula britânica do rule of law comporta quatro dimensões básicas: a observância de um processo justo regulado, quando se tiver de julgar e punir os cidadãos, privando-os da liberdade e da propriedade; a proeminência das leis e costumes do país perante a discricionariedade do poder real; a sujeição de todos os atos do executivo à soberania do parlamento; a igualdade de acesso aos tribunais por parte dos cidadãos, segundo os princípios do direito comum (common law)" (grifo nosso) (SOARES, 2008, p. 68).
} 
natural, mas a exclusividade do direito positivo". Denota-se aqui o caráter qualitativo da diferenciação.

Hans Kelsen (2009), conhecido por ser um positivista normativo devido a sua Teoria Pura do Direito ${ }^{6}$, procurou formular um pensamento jurídico que estivesse livre de qualquer influência externa. Ou seja, é muito visível a separação entre o ser (o que é, de fato, jurídico) e o dever-ser (aquilo que é metafísico, sociológico, cultural etc.). Seu objeto era puramente o direito positivo, e não os ordenamentos jurídicos diversos (desse ou daquele outro país). Segundo o autor, a norma jurídica deve derivar de outra norma jurídica hierarquicamente superior (dessa forma, montando a sua famosa pirâmide) até que se deva pressupor uma norma, a qual ele chama de hipotética fundamental, para funcionar como a fonte de validade de todas as demais.

As definições dessas duas correntes seguem paralelas à discussão existente acerca do Direito e Moral (ponto central de grandes discussões dentro da moderna Ciência do Direito). Sendo o Direito Natural adepto a uma tese monista (em que Direito e Moral se sobrepõem) e o positivismo se identificando como uma tese dualista (estando o Direito e a Moral separados formando 2 sistema de normas) (BOBBIO, 2006, p. 27).

Percebe-se, portanto, que há uma mudança no paradigma. O positivismo, de uma forma geral, veio se preocupar com aquilo que é lícito ou ilícito, deixando de lado a preocupação inerente do direito natural, que é aquela que está na órbita do que é bom e justo.

Com isso, poderia se pensar o positivismo como uma teoria reducionista, uma vez que torna o próprio Direito como algo autoreferencial, ou seja, é Direito aquilo que a lei diz que é Direito. O próprio aspecto formalista desta teoria impede que se faça uma leitura adequada da relação entre Direito e justiça.

Além disso, a tese positivista de que segurança jurídica e certeza seriam suficientes para materializar o Direito não deve prosperar. Elas não são suficientes para se comprovar a sua permanência em vigor. As mudanças permanentes das sociedades exige a incorporação de valores na experiência jurídica (SOARES, 2008, p. 60-61).

\footnotetext{
${ }^{6} \mathrm{O}$ que é pura é a sua teoria, e não o Direito.
} 
As duas correntes de pensamento, quais sejam, positivismo e direito natural reforçam a ideia de que os seres humanos possuem senso de justiça compartilhado? Senso esse que consiga sustentar a ideia ou um sistema complexo de direitos humanos?

Pode-se partir da premissa de que "justiça" é uma virtude natural? A justiça é considerada boa para facilitar a vida (humana, pois somente esses conseguem internalizar leis) em sociedade, por isso, criaram-se regras de convivência social. A justiça também é considerada boa para possibilitar o florescimento da personalidade. Porém, até mesmo as sociedades mais ordenadas são alvo de disfunções, o que é natural.

Tendo em vista que o que é "bom” ou "justo" é uma convenção entre os semelhantes, então não são naturais, isto é, elas precisam ser ensinadas aos seres humanos, cultivadas. "even one's deepest moral convictions are social constructs, which depend exclusively on culture, myth, or ideology; thus, they are fundamentally arbitrary"7(MIKHAIL, 2012,p. 162).

Alcançar uma justiça natural é pura utopia, pois não se pode capturar a essência de um senso absolutamente comum de moralidade de todos os seres humanos. A grande variedade de concepções e crenças sócio-políticas dá origem a múltiplas (e por vezes até concorrentes) concepções de justiça. As normas sociais existem justamente para equalizar comportamentos, tornando-os o mais estável e "previsível” possíveis. Dessa forma, a cooperação entre os indivíduos, dentre outras formas através de contratos (formais ou sociais), se torna possível.

As diversas teorias de justiça são produtos e invenções humanas. Tudo aquilo que deriva delas é considerado artificial, assim como outros produtos da mente humana, a exemplo do próprio positivismo jurídico. Assim, justiça é algo artificial tanto quanto, por exemplo, celulares.

If justice is fairness, then the virtue of justice is the disposition to act in accord with some theory of fairness and that theory is a human artifact. If justice is lawfulness, then the virtue of justice is the disposition to act in accord with the positive laws and social norms of a particular human culture, and those laws and norms are human artifacts. In either case, justice is an artificial virtue (SOLUM, 2006, p. 96).

Mas aquilo que realmente é justo em um determinado tempo e espaço não deveria ser reduzido àquilo que é "legal". Isto é, uma lei pode fazer com que qualquer conduta seja certa,

\footnotetext{
7“Mesmo as convicções morais mais profundas de alguém são construções sociais, que dependem exclusivamente da cultura, do mito ou da ideologia; Assim, são fundamentalmente arbitrários” (tradução nossa).
} 
mas será ela justa?. O que se quer saber, em verdade, é se as leis são de fato justas ou o mais importante: se aquilo que é justo, mas não lei, consegue ser Direito.

\begin{abstract}
A non-democratic legal system, based on the denial of human rights, on extensive poverty, on racial segregation, sexual inequalities, and religious persecution may, in principle, conform to the requirements of the rule of law better than any of the legal systems of the more enlightened Western democracies. This does not mean that it will be better than those Western democracies. It will be an immeasurably worse legal system, but it will excel in one respect: in its conformity to the rule of law (RAZ, 2012, p. 211). ${ }^{8}$
\end{abstract}

Muito embora esse raciocínio faça sentido, hoje, no pós-positivismo (mas principalmente após o debate Hart x Dworkin), os olhos da doutrina internacional foram abertos para uma nova reflexão acerca da função interpretativa do Direito, delineada por uma nova hermenêutica.

A discussão acerca do positivismo se desdobrou em uma discussão entre o positivismo inclusivo (dentre os autores que defendem esse posicionamento estão o próprio L. A. Hart e Will Waluchow) e o positivismo exclusivo (defendido, dentre outros, por Joseph Raz e Scott J. Shapiro), em que se discute a inclusão de um fator moral (mais especificamente dentro da regra de reconhecimento) na explicação dos fenômenos jurídicos.

Nesse sentido, o positivismo inclusivo, de certa maneira, conseguiu superar alguns impasses propostos à teoria positivista em geral, uma vez que conseguiu administrar um fator axiológico (o que, para Dworkin, seria feito por meio de princípios) dentro da sua definição. Assim sendo, o positivismo acabou por acomodar certos preceitos do Direito Natural, abandonando um pouco do seu formalismo.

\title{
4 A SIMILITUDE ENTRE DIREITOS HUMANOS E DIREITO NATURAL: NOVOS RÓTULOS PARA O MESMO PROBLEMA
}

\footnotetext{
${ }^{8} \mathrm{Na}$ tradução livre do autor: "Um sistema jurídico não-democrático, baseado na negação dos direitos humanos, na pobreza extensa, na segregação racial, nas desigualdades sexuais e na perseguição religiosa pode, em princípio, estar em conformidade com os requisitos do Estado de Direito melhor do que qualquer um dos sistemas legais das democracias ocidentais mais esclarecidas. Isso não significa que seja melhor do que as democracias ocidentais. Será um sistema jurídico imensamente pior, mas vai se destacar em um aspecto: na sua conformidade com o Estado de Direito".
} 
Apesar de bastante difundido o "movimento" (se é que pode chamá-lo assim) dos Direitos Humanos ${ }^{9}$, o que se vive hoje, infelizmente, é seu descumprimento como regra.

Sem dúvida, a retórica dos direitos humanos é abundante em hipocrisia oca; É infectado pelo cinismo egoísta e por auto-engano, mas não anula totalmente o valor da crescente aceitação dos direitos humanos na condução das relações internacionais. O hipócrita e a auto-enganação de si mesmos homenageiam os padrões que eles distorcem ao reconhecer através de sua invocação muito hipócrita e enganosa que estes são os padrões apropriados para julgar sua conduta. No entanto, o sucesso da prática dos direitos humanos, como farei referência à gama de atividades que mencionei, coloca um problema para reflexões éticas sobre eles (RAZ, 2007, p. 1) ${ }^{10}$.

É evidente que, na atualidade, mesmo com a diversidade de sistemas jurídicos e políticos, os Direitos Humanos exercem papel de destaque nos cenários nacionais e também no internacional. Por esse motivo, esses direitos aparecem como uma referência em quase todos os textos constitucionais. Esse fato, entretanto, não pode ser tido como uma prova irrefutável da sua efetiva realização, isso porque estão sendo constantemente violados. Para o intuito do presente artigo, será avaliada aqui a fundamentação desses direitos, devendo o problema da eficácia ser objeto de outro estudo.

A fundamentação jurídico-política dos Direitos Humanos, em verdade, foi uma construção ao longo dos anos. Diversos documentos históricos, como por exemplo a Magna Charta Libertatum (1215), o Petition of Rights (1628), o Bill of Rights (1689) e outros, se prestaram para a construção da sua efetiva concretização que, para muitos, se deu através da Revolução Francesa (1789-1799) e da Declaração dos Direitos do Homem e do Cidadão em 1789 (JELLINEK, 2000, p. 126).

\footnotetext{
9،"The failure of the traditional doctrine Human rights practice is not only becoming better established, it is also spreading its wings. An ever growing number of rights are claimed to be human rights, for example, the right to sexual pleasure; the right to sexual information based upon scientific inquiry; the right to comprehensive sexual education. It is declared that all persons have the right to a secure, healthy and ecologically sound environment. Future generations have rights to meet equitably their needs. All persons have the right to protection and preservation of the air, soil, water, sea-ice, flora and fauna, and the essential processes and areas necessary to maintain biological diversity and ecosystems. Some academics argue that there is a human right to globalization" (RAZ, 2007, p. 2).

\begin{abstract}
${ }^{10}$ No original: No doubt human rights rhetoric is rife with hollow hypocrisy; it is infected by self-serving cynicism and by self-deception, but they do not totally negate the value of the growing acceptance of human rights in the conduct of international relations. The hypocrite and the self-deceived themselves pay homage to the standards they distort by acknowledging through their very hypocritical and deceitful invocation that these are the appropriate standards by which to judge their conduct. However, the success of the practice of human rights, as I will refer to the range of activities I have mentioned, poses a problem for ethical reflections about them.
\end{abstract}




\section{DIREITOS HUMANOS COMO RECONSTRUÇÃO DO DIREITO NATURAL SOBRE O POSITIVISMO? VELHOS PROBLEMAS E VELHAS SOLUÇÕES}

Com o término da Segunda Guerra Mundial e em respostas às atrocidades cometidas durante das grandes guerras, os Direitos Humanos começaram a ser internacionalizados (PIOVESAN, 2010, p. 96-97) (daí a criação do nome: Direito Internacional dos Direitos Humanos) e a ganharem destaque nos documentos constitucionais ao redor do mundo. Dessa forma, a comunidade internacional poderia ter maior controle e proteção dos Direitos Humanos - não é à toa que a criação da Organização das Nações Unidas (ONU) se deu em 1945.

Antigamente, o apoio ao movimento de direitos humanos era considerado barato para os Estados-Nações, devido, em parte, à fraqueza dos mecanismos de execução e proteção. Hoje, entretanto, o movimento tornou-se uma nova cruzada cada vez mais forte e capaz de afetar políticas e ações governamentais em graus distintos em muitos países, se não em todos.

O estudo acerca dos Direitos Humanos é delineado por aspectos filosóficos e políticos com os quais devem sempre estar em contato direto até mesmo por uma questão de diplomacia. É por esse motivo que se pode avaliar esses direitos sobre uma perspectiva filosófica e/ou social. Os Direitos Naturais, da mesma forma, podem ser analisados sob uma perspectiva filosóficopolítica, já que, como dito, sua fundamentação transcende o feitio humano ${ }^{11}$.

Retomando a discussão trazida no tópico anterior, querer reduzir os Direitos Humanos àquilo que está positivado consiste em um paradoxo ao seu próprio significado intrínseco, que é uma objeção/crítica ao positivismo. Os projetos contemporâneos de fundamentação dos Direitos Humanos cometem, em sua maioria, o mesmo equívoco que a doutrina dos Direitos Naturais sempre cometeu: tomam o indivíduo racional como o pressuposto para uma teoria sobre uma gênese dos direitos. (SILVA, 2015, p. 150).

Feita essa brevíssima introdução dos Direitos Humanos, pode-se começar a discutir fatores mais intrínsecos a sua estrutura, tal como a discussão acerca da sua universalização ${ }^{12}$.

\footnotetext{
${ }^{11}$ Corroborando com esse posicionamento está o considerado maior jusnaturalista contemporâneo, John Finnis, verbis: "the principles of natural law, thus understood, are traced out not only in moral philosophy or ethics and 'individual' conduct, but also in political philosophy and jurisprudence, in political action, adjudication, and the life of the citizen. For those principles justify the exercise of authority in community. They require, too, that that authority be exercised, in most circumstances, according to the manner conveniently labelled the Rule of Law, and with due respect for the human rights which embody the requirements of justice, and for the purpose of promoting a common good in which such respect for rights is a component" (FINNIS, 2011, p. 23).

${ }^{12}$ Joseph Raz (2009, p. 42) traz um interessante questionamento acerca da universalização: "But if people can have different human rights at different periods, why can it not be the case that people who live today can have different human rights? Why must human rights be synchronically universal?"
} 
Assim como os Direitos Naturais, os Direitos Humanos são conhecidos por sua característica da universalidade.

Sem adentrar a discussão sobre o fato da universalidade ser ou não uma nova forma de imperialismo cultural do ocidente (tema que também merece ser tratado em outro trabalho), avalia-se aqui se é plausível a formulação de um tema, qualquer que seja, universal, tendo em vista uma variedade de sociedades extremamente diversas. Afinal, se a própria lei pode ser injusta, porque também não o pode os direitos humanos? Ou pelo menos imorais de acordo com determinada cultura, já que ambos são criações humanas, e como tais imperfeitas?

Martha Nussbaum (2013, p. 91-93) traz uma lista de 10 capacidades (intrinsecamente relacionadas com a dignidade da pessoa humana -doravante chamada de DPH) consideradas universais que, a priori, seria bem quista por toda a comunidade internacional. É ela:

1) Vida. Ter a capacidade de viver até o fim de uma vida humana de duração normal; não morrer prematuramente, ou antes que a própria vida se veja tão reduzida que não valha a pena vivê-la.

2) Saúde física. Ser capaz de ter boa saúde, incluindo a saúde reprodutiva; de receber uma alimentação adequada; de dispor de um lugar adequado para viver.

3) Integridade física. Ser capaz de se movimentar livremente de um lugar a outro; de estar protegido contra ataques de violência, inclusive agressões sexuais e violência doméstica; dispor de oportunidades para a satisfação sexual e para a escolha em questões de reprodução.

4) Sentidos, imaginação e pensamento. Ser capaz de usar os sentidos, a imaginação, o pensamento e o raciocínio- e fazer essas coisas de um modo "verdadeiramente humano": um modo informado e cultivado por uma educação adequada, incluindo, sem limitações, a alfabetização e o treinamento matemático e científico básico. Ser capaz de usar a imaginação e o pensarnento em conexão com experimentar e produzir obras ou eventos, religiosos, literários, musicais e assim por diante, da sua própria escolha. Ser capaz de usara própria mente de modo protegido por garantias de liberdade de expressão, com respeito tanto à expressão política quanto artística, e liberdade de exercício religioso. Ser capaz de ter experiências prazerosas e evitar dores não benéficas.

5) Emoções. Ser capaz de manter relações afetivas com coisas e pessoas fora de nós mesmos; amar aqueles que nos amam e que se preocupam conosco; sofrer na sua ausência; em geral, ser capaz de amar, de sentir pesar, sentir saudades, gratidão e raiva justificada. Não ter o desenvolvimento emocional bloqueado por medo e ansiedade. (Apoiar essa capacidade significa apoiar formas de associação humana que podem se revelar cruciais para seu desenvolvimento).

6) Razão prática. Ser capaz de formar uma concepção de bem e de ocupar-se com a reflexão crítica sobre o planejamento da própria vida. (Isso inclui proteção da liberdade de consciência e de prática religiosa).

7) Afiliação. 
A) Ser capaz de viver com e voltado para outros, reconhecer e mostrar preocupação com outros seres humanos, ocupar-se com várias formas de interação social; ser capaz de imaginar a situação do outro. (Proteger essa capacidade significa proteger as instituições que constituem e alimentam tais formas de afiliação e também proteger a liberdade de associação e de expressão política).

B) Ter as bases sociais de autorrespeito e não humilhação; ser capaz de ser tratado como um ser digno cujo valor é igual ao dos outros. Isso inclui disposições de não discriminação com base em raça, sexo, orientação sexual, etnia, casta, religião, origem nacional.

8) Outras espécies. Ser capaz de viver uma relação próxima e respeitosa com animais, plantas e o mundo da natureza.

9) Lazer. Ser capaz de rir, brincar, gozar de atividades recreativas.

10) Controle sobre o próprio ambiente.

A) Político. Ser capaz de participar efetivamente das escolhas políticas que governam a própria vida; ter o direito à participação política, proteções de liberdade de expressão e associação.

B) Material. Ser capaz de ter propriedade (tanto de bens imóveis quanto de móveis) e ter direitos de propriedade em base igual à dos outros; ter o direito de candidatar-se a empregos em base de igualdade com os demais; ter a liberdade contra busca e apreensão injustificadas. No trabalho, ser capaz de trabalhar como ser humano, exercendo a razão prática e participando de relacionamentos significativos, de reconhecimento mútuo com demais trabalhadores.

Para o estudo dessas capacidades, deve-se ter em mente que elas "serão consideradas direitos humanos centrais, em função dos quais a justiça social básica é definida enfoque das capacidades" (NUSSBAUM, 2013, p. 204). Indaga-se aqui: será que se pode falar em uma "universal moral grammar" (MIKHAIL, 2007, p. 143) ou até mesmo de um consenso sobreposto rawlsiano (RAWLS, 2011, p. 202)? A verdade é que é (muito) difícil se universalizar, mesmo quando o assunto é Direitos Humanos, pois as diversidades culturais dificultam a execução prática.

Essa problemática, portanto, remete à outra, qual seja: a tentativa de jurispositivação dos Direitos Humanos dentro de um caráter universal (isto é, comum a todos os povos) significaria ignorar completamente a própria heterogeneidade dos Direitos Humanos? Explicase.

A grande variedade desses direitos diz respeito não só, mas também à diferença lógica de tempo e espaço, no sentido de que as pretensões não são as mesmas em todos os lugares ao mesmo tempo. Também responde a heterogeneidade ao caráter, por vezes, contraditório dos 
Direitos Humanos. Ou seja, ao se afirmar determinado Direto, ao mesmo tempo estar-se-á contradizendo (ou no mínimo se contrapondo) a outro Direito diretamente antagônico a ele, pertencente a outro(s) de titular(es).

Essa disparidade é apenas um exemplo dentro de uma gama de discrepâncias dentro de um cenário global. Isso tudo para concluir, por ora, que sejam os valores intrínsecos ("valoresfonte") chamados de Direito Natural, ou Direitos Humanos, eles nunca poderão ser absolutamente universalizados de forma a possibilitar um status de "modus vivendi", o qual se alcança a completude através da diferença.

Em verdade, o referencial de pessoa humana, ou seja, a Dignidade da Pessoa Humana é o "valor-fonte" que se ancora não só na expressão "Direitos Naturais", mas também na "Direitos Humanos", que, inter alia, trouxe as discussões filosóficas inerentes ao ius naturale de volta à tona se revestindo, apenas, de uma nova roupagem. E o fez se aproveitando dos desfechos globais e das atrocidades cometidas nos últimos anos para acalorar as discussões e tentar reviver uma nova "supremacia" dos Direitos Naturais.

Per se, o Direito Natural consegue comportar tanto o plano ontológico e também o deontológico, na medida em que a essência desse direito é o próprio dever-ser. Assim como também o são os Direitos Humanos, o jusnaturalismo tem um quê de incognoscível, pois são frutos de valorações subjetivas com alta carga axiológica.

Muitas são as teorias morais que se enquadram dentro da teoria do direito natural. Da mesma forma, é fácil encaixar "meros" direitos dentro do status de Direitos Humanos. Suas próprias fundamentações não conseguem ser alvo de comprovação empírica. Portanto, é razoável considerar que as mesmas restrições que possivelmente possam ser aplicadas ao Direito Natural, também poderão, ceteris paribus, ser aplicadas aos Direitos Humanos.

\section{CONCLUSÃO}

Tendo em vista o exposto, a contextualização do debate contemporâneo acerca da Lei Natural e sua correspondência com os Diretos Humanos e a crítica oferecida pelo positivismo jurídico restaram claras. Fingir que a teoria dos Direitos Humanos não guarda identidade com a teoria do Direito Natural é simplesmente atualizar velhos conceitos que não se prestaram para 
resolver problemas antigos e não servirá para resolver os de hoje. O que não quer dizer, entretanto, que não deva haver positivação.

Os Direitos Humanos herdaram do Direito Natural seu peso e suas discussões inerentes, que representam um verdadeiro desafio ao positivismo jurídico. As novas discussões entre positivismo inclusivo levam em consideração uma coexistência entre o positivismo e aspectos axiológicos. Os Direitos Humanos vieram ressuscitar algo que está latente (porém não esquecido).

A rivalidade derivada do debate juspositivismo $\mathrm{x}$ jusnaturalismo se acentua na medida em que questões de ordens transcendentais ao seu humano são postas em jogo. O arquétipo positivista, que é entendido como aquele que quer contrapor o saber metafísico e o científico, não consegue, por si só, explicar o extraordinário.

Se o Estado de Direito está ligado ao conceito de "boas leis" (o que quer que isso signifique), então ele requer que suas leis sejam amparadas por algum fundamento normativo que transcenda o próprio ordenamento. Antigamente a "lei divina"/lei natural cumpria esse papel, porém hoje a ideologia mais secular de democracia e dos direitos humanos é a base para a construção do sistema.

O fato de se querer reconhecer Direitos Humanos em documentos escritos ou de ratificálos só confirma a ideia de que o "Direito Natural”, entendido aqui como uma carga valorativa, só consegue operar de maneira satisfatória na contemporaneidade com a ajuda da positividade. A positivação desses direitos, em geral, serve para aumentar o nível de segurança jurídica dentro do Estado de Direito, que por sua vez é necessário para a democracia e boa governança.

\section{BIBLIOGRAFIA}

BOBBIO, Norberto. Jusnatualismo e Positivismo Jurídico. Trad. Jaime A. Clasen. São Paulo: Unesp, 2016.

. O Positivismo Jurídico: Lições de Filosofia do Direito. Trad. Márcio Pugliesi, Edson Bini, Carlos Rodrigues. São Paulo: Ícone, 2006.

DWORKIN, Ronald. Levando o Direito a Sério. São Paulo: Martins Fontes, 2002.

FINNIS, John. Natural Law And Natural Rights. Oxford: Oxford University Press, 2011. 
HART, Herbert. O Conceito de Direito. São Paulo: Martins Fontes, 2009.

JELLINEK, Georg. La Declaración de los Derechos Del Hombre e Del Ciudadano.

México: Universidad Nacional Autónoma de México, 2000.

KELSEN, Hans. Teoria Pura do Direito. 8ª ed. São Paulo: Martins Fontes, 2009.

LAFER, Celso. A Reconstrução dos Direitos Humanos: Um Diálogo com o Pensamento de Hannah Arendt. São Paulo: Companhia das Letras, 1988.

MATTOS, Carlos Lopes de. Santo Tomás de Aquino: Vida e Obra. São Paulo: Nova Cultural, 2000.

MIKHAIL, John. Moral Grammar and Human Rights: Some Reflections on Cognitive Science and Enlightenment Rationalism. In: GOODMAN, Ryan; JINKS, Derek; WOODS, Andrew (orgs). Understanding Social Action, Promoting Human Rights. Oxford University Press, 2012. Disponível em: <https://ssrn.com/abstract=1924915>. Acesso em 28 jul 2017.

MIKHAIL, John. Universal Moral Grammar: Theory, Evidence and the Future. Trends in Cognitive Sciences, Vol. 11 No. 4. Disponível em:

<http://tuvalu.santafe.edu/ bowles/UniversalMoralGrammar.pdf>. Acesso em: 27 jul 2017.

NUSSBAUM, Martha. Fronteiras da Justiça: Deficiência, Nacionalidade e Pertencimento à Espécie. Trad. Susana de Castro. São Paulo: Martins Fontes, 2013.

PIOVESAN, Flávia. Direito ao Desenvolvimento: Desafios Contemporâneos. In: PIOVESAN, Flávia; SOARES, Inês Prado (coord.). Direito ao Desenvolvimento. Belo Horizonte: Fórum, 2010.

RAWLS, John. O Liberalismo Político. São Paulo: WMF Martins Fontes, 2011.

RAZ, Joseph. Human Rights in the Emerging World Order.Oxford Legal Studies Research Paper No. 47/2009. Disponível em: 〈https://ssrn.com/abstract=1497055>. Acesso em: 08 ago. 2017.

Human Rights Without Foundations. Oxford Legal Studies Research Paper No. 14/2007. Disponível em: <https://ssrn.com/abstract=999874>. Acesso em: 28 jul 2017. 
. The Rule of Law and its Virtue. In: RAZ, Joseph. The authority of law: essays on law and morality. Clarendon Press, 2012.

SOARES, Ricardo Maurício F. O Discurso Constitucional da Dignidade da Pessoa

Humana: Uma Proposta de Concretizaçâo do Direito Justo no Pós-Positivismo

Brasileiro. 2008. 277fls. Tese (Doutorado em Direito) - Universidade Federal da Bahia.

Salvador, 2008.

SOLUM, Lawrence. Natural Justice. American Journal of Jurisprudence, Vol. 51, p. 65-105, 2006. Disponível em: <https://ssrn.com/abstract=959646>. Acesso em: 27 jul 2017.

SILVA, André Luiz O. Os Direitos Humanos e o Estado "natural" de Fundamentação dos Direitos. Sequiência (Florianópolis), p. 133-154, n. 71, dez, 2015.

WEBER, Max. A Ciência como Vocação. In: WEBER, Max. Ensaios de Sociologia. 5 ed. Rio de Janeiro: LTC, 1982. 